\title{
Correction to: A comprehensive comparison of sex-inducing activity in asexual worms of the planarian Dugesia ryukyuensis: the crucial sex-inducing substance appears to be present in yolk glands in Tricladida
}

Haruka Nakagawa ${ }^{1 \dagger}$, Kiyono Sekii ${ }^{1 \dagger}$, Takanobu Maezawa², Makoto Kitamura³ , Soichiro Miyashita', Marina Abukawa', Midori Matsumoto ${ }^{4}$ and Kazuya Kobayashi*

\section{Correction}

Following publication of the original article [1] the author advised that unfortunately in the 'Discussion' section the letters ' $L$ ' and ' $D$ ' in some 'enantiomer' expressions were not written in the format of 'small capitals'. Rather, they were written as lower-case letters.

This formatting is an important nomenclature in chemistry, the author confirmed, advising:

"Enantiomers (mirror-image isomer) of amino acids (L or D) is always expressed by 'small capitals' "

As such, the original article [1] has been corrected to reflect this.

\section{Author details}

${ }^{1}$ Department of Biology, Faculty of Agriculture and Life Science, Hirosaki University, Aomori, Japan. ${ }^{2}$ Advanced Science Course, Department of Integrated Science and Technology, National Institute of Technology, Tsuyama College, Okayama, Japan. ${ }^{3}$ Center for Integrated Medical Research, School of Medicine, Keio University, Tokyo, Japan. ${ }^{4}$ Department of Biosciences and Informatics, Keio University, Yokohama, Japan.
Published online: 31 August 2018

\section{Reference}

Nakagawa H, Sekii K, Maezawa T, Kitamura M, Miyashita S, Abukawa M, Matsumoto M, Kobayashi K. A comprehensive comparison of sex-inducing activity in asexual worms of the planarian Dugesia ryukyuensis: the crucial sex-inducing substance appears to be present in yolk glands in Tricladida. Zoological Lett. 2018:4:14. https://doi.org/10.1186/s40851-018-0096-9.

* Correspondence: kobkyram@hirosaki-u.ac.jp

${ }^{\dagger}$ Haruka Nakagawa and Kiyono Sekii contributed equally to this work.

'Department of Biology, Faculty of Agriculture and Life Science, Hirosaki

University, Aomori, Japan

Full list of author information is available at the end of the article

(c) The Author(s). 2018 Open Access This article is distributed under the terms of the Creative Commons Attribution 4.0 International License (http://creativecommons.org/licenses/by/4.0/), which permits unrestricted use, distribution, and reproduction in any medium, provided you give appropriate credit to the original author(s) and the source, provide a link to the Creative Commons license, and indicate if changes were made. The Creative Commons Public Domain Dedication waiver (http://creativecommons.org/publicdomain/zero/1.0/) applies to the data made available in this article, unless otherwise stated. 